\title{
Development of type 1 diabetes in a patient treated with anti-TNF- $\alpha$ therapy for active rheumatoid arthritis
}

\author{
C. J. Tack • F. S. Kleijwegt • P. L. C. M. Van Riel • \\ B. O. Roep
}

Received: 25 February 2009 / Accepted: 5 April 2009 /Published online: 14 May 2009

(C) The Author(s) 2009. This article is published with open access at Springerlink.com

Keywords Anti-TNF- $\alpha$ - Autoimmune $\cdot$ GAD .

Pathogenesis $\cdot$ Rheumatoid arthritis $\cdot$ Type 1 diabetes

\begin{abstract}
Abbreviations
DAS28 28 Joint disease activity score

GADA GAD autoantibody
\end{abstract}

To the Editor: Excess levels of TNF- $\alpha$ have been associated with certain autoimmune diseases. Prolonged administration of TNF- $\alpha$ antibody is used to effectively treat chronic inflammatory diseases such as rheumatic diseases and Crohn's disease [1]. Anti-TNF- $\alpha$ drugs have clearly been shown to suppress disease activity in rheumatoid arthritis, and are a candidate therapy for immune intervention in type 1 diabetes. We report a case of a patient with juvenile idiopathic arthritis, who developed type 1 diabetes while receiving anti-TNF- $\alpha$ therapy.

\section{J. Tack $(\bowtie)$}

Department of Internal Medicine, 463,

Radboud University Nijmegen Medical Centre,

P.O. Box 9101, 6500 HB Nijmegen, the Netherlands

e-mail: c.tack@aig.umcn.nl

F. S. Kleijwegt • B. O. Roep

Department of Immunohaematology and Blood Transfusion,

Leiden University Medical Centre,

Leiden, the Netherlands

P. L. C. M. Van Riel

Department of Rheumatology,

Radboud University Nijmegen Medical Centre,

Nijmegen, the Netherlands

\section{Case history and examination}

A 35-year-old woman (HLA-DR3-DQ2 homozygous) was diagnosed with juvenile idiopathic arthritis (rheumatoid factor-positive) at 15 years of age. Her mother had been diagnosed with type 1 diabetes at 29 years of age. Over the years, the disease appeared to be largely resistant to therapy; despite treatment with sulfasalazine, auranofin, hydroxychloroquine, methotrexate, azathioprine, penicillamine, prednisone and ciclosporin consecutively, she developed severe joint destruction for which she received several joint replacements, including both shoulders and knees. In 1997, she participated in a trial on TNF- $\alpha$ antibody therapy (adalimumab) for approximately half a year, without clear benefit. In 1999, she received five cyclophosphamide infusions, which had only a partial, temporary effect. The only approach that suppressed her arthritis was the regular injection of methylprednisolone. At the end of 2000, she was started on etanercept, a subcutaneously administered TNF- $\alpha$ antagonist, at a dose of $25 \mathrm{mg}$, twice a week. This treatment had a clear beneficial effect on her arthritis. Her 28 joint disease activity score (DAS28), a validated composite score [2], substantially decreased. Methylprednisolone administration was successfully tapered before finally being completely discontinued, and she needed fewer non-steroidal anti-inflammatory drugs. In 2000 and 2001, measured plasma glucose levels (non-fasting) were 5.7 and $6.1 \mathrm{mmol} / \mathrm{l}$. The patient continued to report a beneficial effect of etanercept treatment, although the therapy did not completely suppress her joint inflammation.

In 2003, she noticed polydipsia and polyuria, genital candida, generalised fatigue and a $3 \mathrm{~kg}$ loss of body weight. 
Her blood glucose level was $>25 \mathrm{mmol} / \mathrm{l}$, and her $\mathrm{HbA}_{1 \mathrm{c}}$ was $11.6 \%$ (reference value $4.8-6.1 \%$ ). The level of GAD autoantibody (GADA), determined by ELISA (RSR, Cardiff, UK), was very high at $1,312 \mathrm{U} / \mathrm{ml}$ (normal value $<5 \mathrm{U} / \mathrm{ml}$ ). The patient was put on multiple daily insulin injections (combination insulin aspart and insulin glargine), which resulted in the rapid relief of symptoms, normalisation of blood glucose levels and $\mathrm{HbA}_{1 \mathrm{c}}$, and an increase in weight. The patient currently requires a daily dose of insulin of $\sim 0.75 \mathrm{U} / \mathrm{kg}$.

To determine whether the appearance of GADA preceded etanercept therapy, earlier samples were screened for this antibody. Retrospective serology revealed the presence of GADA in 1997, prior to the patient's participation in the adalimumab trial. During the course of TNF- $\alpha$ antibody administration, the GADA titres rose tenfold, to exceptionally high titres (Fig. 1). IA-2 autoantibodies were not detectable at any time point.

\section{Conclusions}

Our case report illustrates important points concerning the effect of anti-TNF- $\alpha$ therapy in the context of the development of type 1 diabetes. First, we confirm a clear beneficial effect of anti-TNF- $\alpha$ therapy on rheumatoid arthritis. Second, anti-TNF- $\alpha$ therapy did not prevent the development or the progression of type 1 diabetes.

Evidence has accumulated from clinical trials that anti-TNF- $\alpha$ therapies can, under certain circumstances, promote rather than quell certain forms of autoimmunity [3]. In rheumatoid arthritis, therapy with diverse therapeutic forms of TNF- $\alpha$ antagonists is associated with relatively common and detectable autoimmune adverse events, such as multiple sclerosis, lupus and diabetes [1]. Prior to the present report, a case of type 1 diabetes was reported in a 7-year-old girl undergoing treatment for juvenile rheumatoid arthritis with a TNF- $\alpha$ antagonist (etanercept) [4].

There are indications that TNF- $\alpha$ may play a dual role in type 1 diabetes. Studies on animal models of type 1 diabetes have shown that TNF- $\alpha$ suppression is essential for progression to autoimmune diabetes. Anti-TNF- $\alpha$ appears to have a rather narrow therapeutic window in NOD mice. Anti-TNF- $\alpha$ treatment before 3 weeks of age induced immunological tolerance to islet cell proteins, while administration of anti-TNF- $\alpha$ treatment at 4 weeks of age or later resulted in the accelerated development of diabetes, producing an increased incidence [5]. Although we appreciate the limitations of animal studies [6], these reports demonstrate that TNF- $\alpha$ can serve as a double-edged sword in autoimmune diabetes by positively or negatively regulating peripheral $\mathrm{T}$ cell tolerance to beta cell antigens.

In patients with rheumatoid arthritis, anti-TNF- $\alpha$ therapy has been found to improve the suppressive abilities of regulatory $\mathrm{T}$ cells [7]. Although this feature could benefit type 1 diabetic patients in whom regulatory $\mathrm{T}$ cell function has been shown to be impaired [8], it was not found to do so in the case reported here.

We propose that the use of anti-TNF- $\alpha$ therapies such as etanercept appears to be ineffective for the prevention of type 1 diabetes. Although there is currently no evidence that such a therapy precipitates type 1 diabetes, this possibility cannot be ruled out, and care should be taken in extrapolating the beneficial effects of anti-TNF- $\alpha$ therapies in other autoimmune diseases to their application in type 1 diabetes.

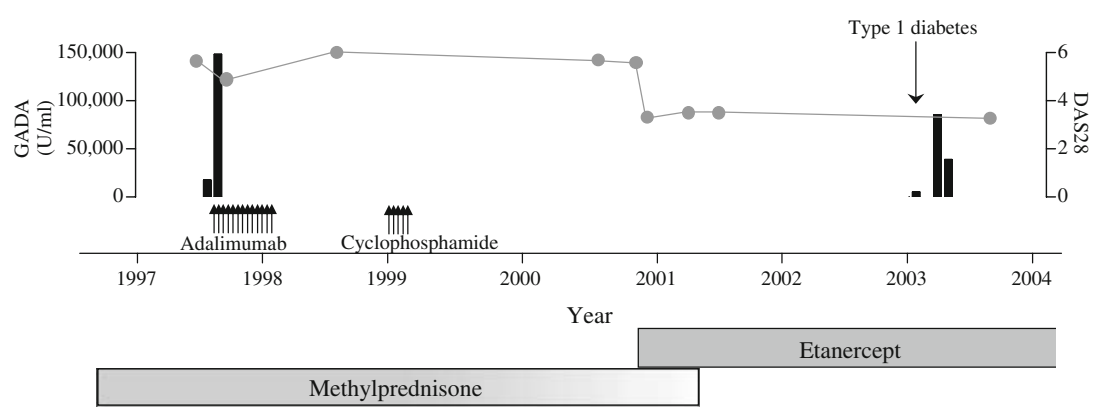

Fig. 1 Time course of findings. The $y$-axis on the left indicates the level of GADA (data shown as bars). The $y$-axis on the right indicates the DAS28 score (data shown as a solid line); a score of $<3.2$ reflects low disease activity; a score of 3.2-5.1 reflects moderate disease activity and a score of $>5.1$ reflects high disease activity. The bar indicating methylprednisone is lighter on the right-hand side to denote tapering of the treatment 
Acknowledgements We thank C. Popa (Department of Rheumatology, Radboud University Nijmegen Medical Centre, the Netherlands) for retrieving stored blood samples. B. O. Roep is supported by a VICI award from the Netherlands Organisation of Health Research and Development (ZonMW).

Duality of interest The authors declare that there is no duality of interest associated with this manuscript.

Open Access This article is distributed under the terms of the Creative Commons Attribution Noncommercial License which permits any noncommercial use, distribution, and reproduction in any medium, provided the original author(s) and source are credited.

\section{References}

1. Feldmann M, Maini RN (2003) Lasker Clinical Medical Research Award: TNF defined as a therapeutic target for rheumatoid arthritis and other autoimmune diseases. Nat Med 9:1245-1250
2. van Gestel AM, Haagsma CJ, van Riel PL (1998) Validation of rheumatoid arthritis improvement criteria that include simplified joint counts. Arthritis Rheum 41:1845-1850

3. Kodama S, Davis M, Faustman DL (2005) The therapeutic potential of tumor necrosis factor for autoimmune disease: a mechanistically based hypothesis. Cell Mol Life Sci 62:1850-1862

4. Bloom BJ (2000) Development of diabetes mellitus during etanercept therapy in a child with systemic-onset juvenile rheumatoid arthritis. Arthritis Rheum 43:2606-2608

5. Yang XD, Tisch R, Singer SM et al (1994) Effect of tumor necrosis factor $\alpha$ on insulin-dependent diabetes mellitus in NOD mice. I. The early development of autoimmunity and the diabetogenic process. J Exp Med 180:995-1004

6. Roep BO, Atkinson M, von Herrath M (2004) Satisfaction (not) guaranteed: re-evaluating the use of animal models of type 1 diabetes. Nat Rev Immunol 4:989-997

7. Toubi E, Kessel A, Mahmudov Z, Hallas K, Rozenbaum M, Rosner I (2005) Increased spontaneous apoptosis of $\mathrm{CD} 4^{+} \mathrm{CD} 25^{+} \mathrm{T}$ cells in patients with active rheumatoid arthritis is reduced by infliximab. Ann N Y Acad Sci 1051:506-514

8. Lindley S, Dayan CM, Bishop A, Roep BO, Peakman M, Tree TI (2005) Defective suppressor function in $\mathrm{CD} 4^{+} \mathrm{CD} 25^{+} \mathrm{T}$ cells from patients with type 1 diabetes. Diabetes 54:92-99 